NASA/TM—2007-214975

(245)

Reliability and Creep/Fatigue Analysis of a CMC Component

Pappu L. N. Murthy

Glenn Research Center, Cleveland, Ohio

Subodh K. Mital

The University of Toledo, Toledo, Ohio

John Z. Gyekenyesi

N\&R Engineering, Parma Heights, Ohio

John P. Gyekenyesi

Glenn Research Center, Cleveland, Ohio 


\section{NASA STI Program . . . in Profile}

Since its founding, NASA has been dedicated to the advancement of aeronautics and space science. The NASA Scientific and Technical Information (STI) program plays a key part in helping NASA maintain this important role.

The NASA STI Program operates under the auspices of the Agency Chief Information Officer. It collects, organizes, provides for archiving, and disseminates NASA's STI. The NASA STI program provides access to the NASA Aeronautics and Space Database and its public interface, the NASA Technical Reports Server, thus providing one of the largest collections of aeronautical and space science STI in the world. Results are published in both non-NASA channels and by NASA in the NASA STI Report Series, which includes the following report types:

- TECHNICAL PUBLICATION. Reports of completed research or a major significant phase of research that present the results of NASA programs and include extensive data or theoretical analysis. Includes compilations of significant scientific and technical data and information deemed to be of continuing reference value. NASA counterpart of peer-reviewed formal professional papers but has less stringent limitations on manuscript length and extent of graphic presentations.

- TECHNICAL MEMORANDUM. Scientific and technical findings that are preliminary or of specialized interest, e.g., quick release reports, working papers, and bibliographies that contain minimal annotation. Does not contain extensive analysis.

- CONTRACTOR REPORT. Scientific and technical findings by NASA-sponsored contractors and grantees.
- CONFERENCE PUBLICATION. Collected papers from scientific and technical conferences, symposia, seminars, or other meetings sponsored or cosponsored by NASA.

- SPECIAL PUBLICATION. Scientific, technical, or historical information from NASA programs, projects, and missions, often concerned with subjects having substantial public interest.

- TECHNICAL TRANSLATION. Englishlanguage translations of foreign scientific and technical material pertinent to NASA's mission.

Specialized services also include creating custom thesauri, building customized databases, organizing and publishing research results.

For more information about the NASA STI program, see the following:

- Access the NASA STI program home page at http://www.sti.nasa.gov

- E-mail your question via the Internet to help@sti.nasa.gov

- Fax your question to the NASA STI Help Desk at 301-621-0134

- Telephone the NASA STI Help Desk at 301-621-0390

- Write to: NASA Center for AeroSpace Information (CASI) 7115 Standard Drive Hanover, MD 21076-1320 
NASA/TM-2007-214975

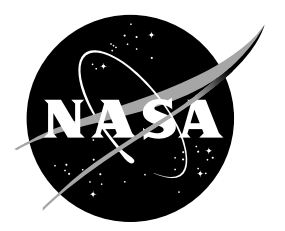

\section{Reliability and Creep/Fatigue Analysis of a CMC Component}

Pappu L. N. Murthy

Glenn Research Center, Cleveland, Ohio

Subodh K. Mital

The University of Toledo, Toledo, Ohio

John Z. Gyekenyesi

N\&R Engineering, Parma Heights, Ohio

John P. Gyekenyesi

Glenn Research Center, Cleveland, Ohio

Prepared for

Turbo Expo 2007

sponsored by the American Society of Mechanical Engineers

Montreal, Canada, May 14-17, 2007

National Aeronautics and

Space Administration

Glenn Research Center

Cleveland, Ohio 44135 
Level of Review: This material has been technically reviewed by technical management.

Available from

NASA Center for Aerospace Information

7115 Standard Drive

Hanover, MD 21076-1320
National Technical Information Service 5285 Port Royal Road Springfield, VA 22161

Available electronically at http://gltrs.grc.nasa.gov 


\title{
Reliability and Creep/Fatigue Analysis of a CMC Component
}

\author{
Pappu L.N. Murthy \\ National Aeronautics and Space Administration \\ Glenn Research Center \\ Cleveland, Ohio 44135 \\ Subodh K. Mital \\ The University of Toledo \\ Toledo, Ohio 43606 \\ John Z. Gyekenyesi \\ N\&R Engineering \\ Parma Heights, Ohio 44130 \\ John P. Gyekenyesi \\ National Aeronautics and Space Administration \\ Glenn Research Center \\ Cleveland, Ohio 44135
}

\begin{abstract}
High temperature ceramic matrix composites (CMC) are being explored as viable candidate materials for hot section gas turbine components. These advanced composites can potentially lead to reduced weight and enable higher operating temperatures requiring less cooling; thus leading to increased engine efficiencies. There is a need for convenient design tools that can accommodate various loading conditions and material data with their associated uncertainties to estimate the minimum predicted life as well as the failure probabilities of a structural component. This paper presents a review of the life prediction and probabilistic analyses performed for a CMC turbine stator vane. A computer code, NASALife, is used to predict the life of a 2-D woven silicon carbide fiber reinforced silicon carbide matrix $(\mathrm{SiC} / \mathrm{SiC})$ turbine stator vane due to a mission cycle which induces low cycle fatigue and creep. The output from this program includes damage from creep loading, damage due to cyclic loading and the combined damage due to the given loading cycle. Results indicate that the trends predicted by NASALife are as expected for the loading conditions used for this study. In addition, a combination of woven composite micromechanics, finite element structural analysis and Fast Probability Integration (FPI) techniques has been used to evaluate the maximum stress and its probabilistic distribution in a CMC turbine stator vane. Input variables causing scatter are identified and ranked based upon their sensitivity magnitude. Results indicate that reducing the scatter in proportional limit strength of the vane material has the greatest effect in improving the overall reliability of the CMC vane.
\end{abstract}

\section{Introduction}

Advanced high temperature CMC have been recognized as viable candidate materials for propulsion system components. The development of these materials is being pursued and continues to be the focus of much research work (ref. 1). Use of these materials in engine components allows for higher operating temperatures leading to higher thermal efficiency, higher specific power and potentially reduced emissions. These objectives can be accomplished mainly by raising the turbine inlet temperature and reducing or eliminating cooling of the turbine blades, vanes and combustors. Conventional materials require a large amount of cooling, thereby reducing the thermal efficiency. CMC's have desirable 
properties such as lighter weight, and higher thermal stability compared to the conventional metallic materials. Hence, one can surmise that CMC's can perform well at much higher temperatures without taking undue penalty in efficiency, with reduced structural weight. The need to reduce maintenance costs and down time makes life prediction an indispensable part of the design process. The task of accurately determining the fatigue life of an engine component in service has become increasingly complex. This results, in part, from the complex missions which are now routinely considered during the design process. These missions include large variations of multiaxial stresses and temperatures experienced by critical engine parts.

Due to the brittle nature of the CMC constituents, complex architectures and the intricate processing conditions, the properties of CMCs show considerable scatter. Reproducibility is a major issue and concern, as $\mathrm{SiC} / \mathrm{SiC}$ composites typically show substantial amount of scatter in the first matrix cracking strength (proportional limit strength taken at $0.005 \%$ offset strain) as well as the ultimate strength measurements (ref. 2). Furthermore, variations and uncertainties are usually present in geometry, thermal properties and loading conditions as well. Consequently, structural designs based solely upon the mean values for the material properties and geometrical variables subjected to deterministic loads may be nonconservative and may lead to unexpected premature failures. This is due to the fact that the maximum stresses in critical locations exceed the proportional limit strength thereby violating the design constraint. Thus the uncertainties add additional concerns regarding the reliability of the vane performance under the service conditions that need to be quantified.

This paper describes a review of the life prediction and probabilistic analyses for a CMC turbine stator vane subjected to typical operating conditions, performed during the last five years at NASA Glenn Research Center by the authors.

\section{Vane Fabrication/Testing /Analysis}

Vane subelements were fabricated from a two-dimensional five-harness satin weave silicon carbide fiber reinforced silicon carbide matrix $(\mathrm{SiC} / \mathrm{SiC})$ composite and were coated with an environmental barrier coating (EBC). In order to address realistic critical design features of a turbine airfoil, the vane subelement cross section was derived from an existing production aircraft engine vane. A unique woven cloth configuration was used to provide a sharp trailing edge with continuous fiber reinforcement. A vane subelement manufactured in this study, with a height of $50 \mathrm{~mm}$, and a cord length of $50 \mathrm{~mm}$, as shown in figure 1. All vanes were manufactured with the chemical vapor infiltrated (CVI)/slurry-cast/melt infiltrated $\mathrm{SiC} / \mathrm{SiC}$ material system using Sylramic ${ }^{\mathrm{TM}} \mathrm{SiC}$ fiber reinforcing cloth (ref. 3). The tests were conducted in a High Pressure Burner Rig (HPBR) that simulated the high temperature engine service environment

(ref. 3). Prior to testing, computational fluid dynamics (CFD) and finite element analyses were performed to predict the temperature and stress conditions present in the vane during rig testing (ref. 4). Calculated in-plane tensile stress values ranged from a value of $27 \mathrm{MPa}$ in the axial direction to a maximum transverse or "hoop" stress of $105 \mathrm{MPa}$. The predicted inter-laminar tensile (ILT) stresses were found to be high for the two-dimensional woven material, although in a very small area. Because of this, the vane was reinforced with some through-thickness fibers (because of the unique geometry at the critical location) that are likely to provide a higher ILT strength than obtained in a 2-D flat specimen. Therefore, even though ILT stresses were of concern, because of the small region and the additional reinforcement provided, they were not considered to be a major design issue (ref. 4). In this work, analysis is focused primarily on the hoop stress since measured data is readily available for in-plane modulus and proportional limit strength. Based upon this data, the statistics pertaining to strength and modulus could be established. Limited data was generated for fatigue, creep (ref. 5) and property scatter using $\mathrm{SiC} / \mathrm{SiC}$ composite coupons under NASA's Ultra Efficient Engine Technology (UEET) program. 


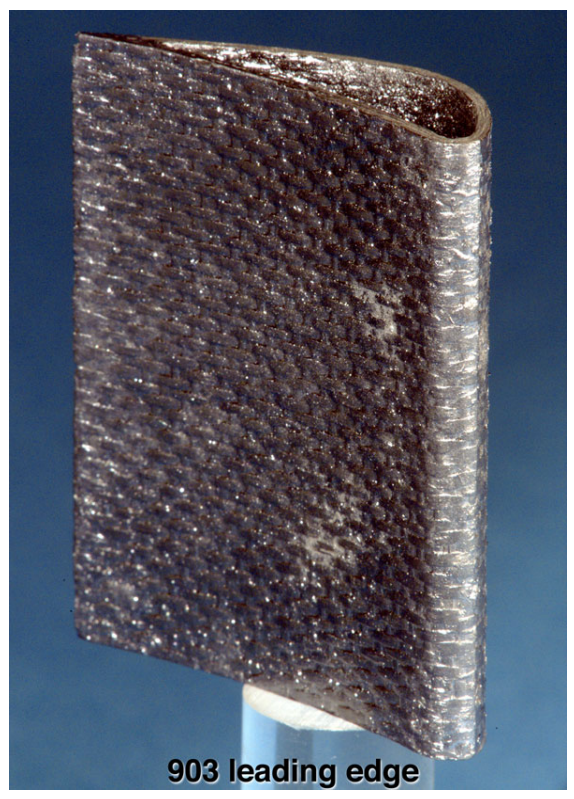

Figure 1.-Ceramic matrix composite turbine stator vane.

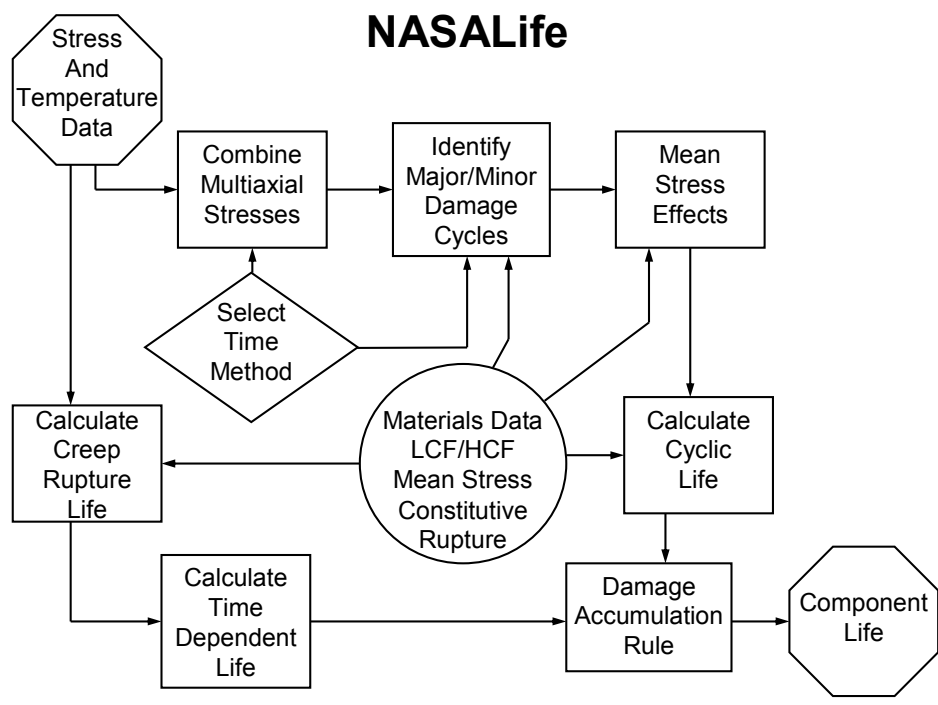

Figure 2.-A Flowchart for NASALife

\section{NASALife-Component Fatigue and Creep Life Prediction Program}

NASALife computer program was developed at General Electric Aircraft Engines (GEAE) under the NASA's Enabling Propulsion Materials (EPM) program. The code was an adaptation of GEAE's proprietary metallic component life prediction code written in an attempt to provide a convenient software package to the designer for determining the life of a CMC component under creep and cyclic thermomechanical loading. NASALife was developed further by N\&R Engineering under NASA's UEET program and used to analyze a CMC turbine stator vane to determine its applicability to composite structures. NASALife is a computer code that requires as input a complete mission stress and temperature profiles during a typical mission. Also required for input are a stress versus life data, a Walker exponent (ref. 6), and the nonlinear stress-strain curve information. The program will then compute the major low cycle fatigue (LCF) cycle, identify all subsequent minor cycles, and finally predict an LCF life corresponding to the given mission. In addition, NASALife can also estimate life relative to creep rupture and life due to the combined effect of LCF and creep (ref. 7). Figure 2 shows a system flowchart for the NASALife computer program.

The fatigue data input contains a series of values for stress and life (S-N curves) at various temperatures. Extrapolation beyond either the maximum temperature or maximum stress of the fatigue data is not permitted. The lowest temperature LCF data is used to determine failure when the mission temperature is below the lowest available data temperature. The LCF life is determined for a given stress amplitude by interpolation of the data file.

Engine components perform under multiaxial stress fields. Multiaxial stresses are converted into an equivalent uniaxial stress in NASALife using modified von Mises method (ref. 7). This conversion included the treatment of both the mean stress, $\sigma_{\mathrm{m}}$, and the stress amplitude, also referred to as the alternating stress, $\sigma_{\mathrm{a}}$. Most components operate with a varying mean stress occurring during their cyclic mission.

The varying load over time during a typical mission is decomposed into cyclic loading of different amplitudes with a rainflow counting technique as presented by Endo (ref. 8). The rainflow counting technique is a standardized cycle counting method as per American Society for Testing and Materials (ASTM) E 1049-85. A common rainflow approach is to use the effective stress at the end points of a 
particular cycle. This will properly calculate the magnitude of the stress amplitude, but does not take into account the influence of the mean stress of the cycle or the variation of temperature during the cycle.

Consequently, NASALife uses a damage rainflow approach instead.

Damage counting schemes identify the most damaging cycle based on the stress and temperature data. In NASALife, a damage counting algorithm is used to identify the most damaging major cycle. The most damaging major cycle is determined by evaluating every combination of mission points, $\mathrm{N} \cdot(\mathrm{N}-1)$ permutations for $\mathrm{N}$ mission points, to find the combination which will produce the lowest life. The life for each subcycle is calculated using one of the multiaxial methods and the mean stress models within NASALife. All subsequent minor cycles are then identified using the traditional stress rainflow techniques.

This damage rainflow approach can select any point in a mission, not necessarily a maximum or minimum stress. A good example of this would be a relatively slow mechanical ramp loading in combination with a rapidly increasing temperature profile where the temperature reaches a maximum prior to the peak mechanical load. If the fatigue life of the material in question decreases with increasing temperature, an intermediate stress point at a high temperature might be in the most damaging cycle.

The fatigue life for a particular stress can be determined from the appropriate LCF curve. The durability life for the mission is obtained by combining the LCF damage of each of the individual cycles using Miner's rule (ref. 9).

NASALife provides a calculated creep rupture life if creep rupture data is included in the input file. A very simple integration over the mission is performed. The step size is determined based on the larger of the time increment or the stress increment. Rupture time is calculated for each increment. The rupture data may either be tables of temperature and stress versus life, or Larson-Miller parameters (ref. 10). The total damage caused by a mission is the sum of the damage due to cyclic fatigue and the damage due to creep.

Design engineers must often consider factors other than those discussed in this document in determining the fatigue life of their components. Some of these issues are:

a) Time dependent deformation

b) Low cycle fatigue ( $\mathrm{LCF}$ )/high cycle fatigue (HCF) Interaction

c) Composite material failure mechanisms

Although these factors may be important, until methods are established and verified for these effects they will not be included in NASALife.

\section{CMC Stator Vane Example}

A CMC stator vane was chosen to illustrate the usage of NASALife computer code in predicting the expected life. The complete details of this analysis can be found in reference 11. The mechanical and other high temperature material properties database is limited due to the fact the material system is relatively new. As a result, for this study the range of data was expanded by extrapolation. Higher and lower stresses were linearly extrapolated using the log of life. Figure 3 shows the applied load cycle that was used to obtain the LCF data in the laboratory. The loading was repeated until complete fracture of the specimen was observed. Data from low cycle fatigue tests, creep rupture tests, and static tensile tests are used as the reference for predicting the number of missions a component can survive under a given thermo-mechanical loading condition. Several analyses consisting of a number of mission profiles of temperature and mechanical loading were conducted using the program. It was seen that at higher temperatures $\left(>1100{ }^{\circ} \mathrm{C}\right)$, creep becomes a significant part of the failure process when considering the life of a thermo-mechanically loaded component. For example, at 97.2 MPa applied constant stress when the hold duration was varied from 5 seconds to 4 hours, the number of missions relative to creep damage reduced from 22532 to 42 . 

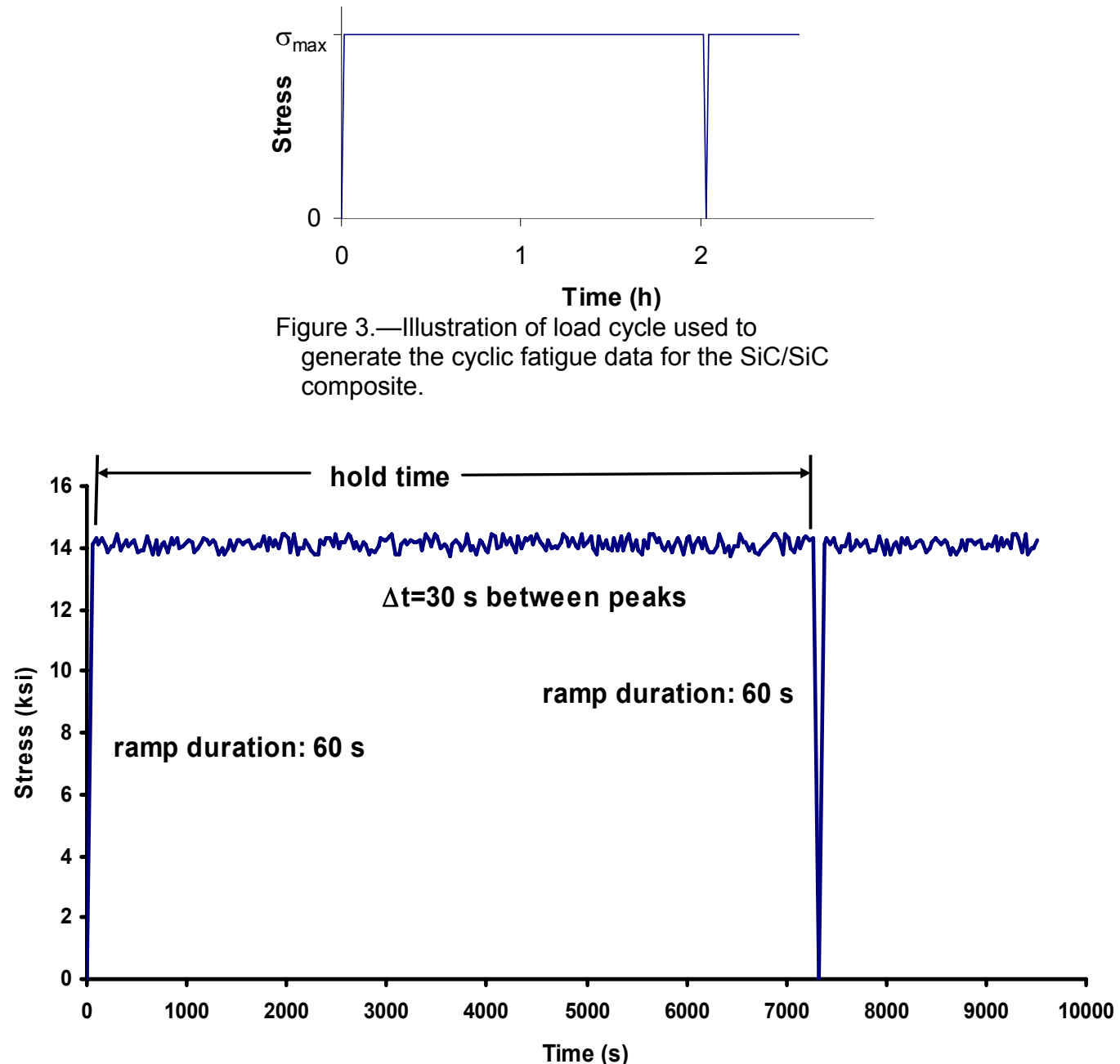

Figure 4.-A sample mission loading with a mean stress of $14 \mathrm{ksi}$ and superimposed random load of $\pm 0-2.5 \%$. The mission consists of the ramp up, hold, and ramp down.

In another sample loading case, the magnitude of the maximum load of an applied random load was increased. Two load cases included are (1) a constant load of $14 \mathrm{ksi}$; and (2) a load of $14 \mathrm{ksi}$. superimposed with random fluctuations of $\pm 0.35 \mathrm{ksi}$ as shown in figure 4 . The load peak to peak duration was held constant at 30 seconds. A typical mission with its load curve is illustrated in figure 4. NASALife typically outputs missions to failure due to creep, due to cyclic fatigue and the combined creep/fatigue effect. The number of mission cycles relative to creep was constant at 84 mission cycles for both load cases as expected. However, the number of mission cycles with respect to the cyclic fatigue loading reduced from 811 , for the constant loading case, down to 42 , for the load case with superimposed small random fluctuations. The combined creep/fatigue effect resulted in 76 mission cycles to failure, for load case 1, and 28 mission cycles to failure for the second load case. The life prediction results from NASALife showed expected trends. Varying the hold duration at high temperatures while keeping the stress constant did provide the expected results of increased damage due to creep while the fatigue damage stayed constant. On the other hand, superimposing a low magnitude variable load over the hold stress and altering the frequency of the variable load had minimal effect on creep but increased the damage due to the cyclic loading. 


\section{Probabilistic Analysis}

The need to account for uncertainties in engineering design has long been recognized. No structure can be guaranteed to be absolutely safe because of the unpredictability of the loads, uncertainties in insitu material properties, use of simplified assumptions in the analysis, including the limitations of the numerical methods used and human factors (errors and omissions). Nevertheless, the probability of failure is usually required to be shown to be within a specified acceptable range for each specific application. Therefore, the estimation of failure probability and risk assessment of a structure becomes an important task for the design/analysis engineers.

As mentioned earlier, the measured $\mathrm{SiC} / \mathrm{SiC}$ material strength and the modulus showed a substantial amount of scatter. The deterministic analyses (ref. 4), specifically near the trailing edge region, indicated that the most critical stresses are in-plane hoop stresses. These stresses are affected primarily by the inplane stiffness of the material as well as by the loading conditions. Furthermore failure is defined by comparing these stresses with the corresponding stress allowables (i.e., proportional limit strength in this case). These two measured material properties show considerable scatter. Design/analysis solely based upon mean values for these properties, therefore, might lead to unexpected failures during the rig testing due to the wide scatter range. Consequently, it was decided to perform a probabilistic (risk) analysis to quantify the probability of vane performance not meeting the design requirement, which is referred to as failure (i.e., the hoop stress exceeding the proportional limit strength). Two cases for probabilistic analysis were evaluated:

\section{Case I}

Only the material Young's modulus, Poisson's ratio, coefficient of thermal expansion and proportional limit strength are considered as independent random variables. These parameters could potentially be correlated. However, extensive data is needed to establish the degree of correlation, if present. Among these variables the strength and modulus statistics are based upon the measured data. Hence, their distribution is derived from this data. Probabilistic distribution related parameters are assumed for the remaining variables. All other pertinent parameters (e.g., material thickness, gas temperature or other loading parameters) are considered deterministic in this evaluation.

\section{Case II}

In addition to the variables considered in case I, two other parameters related to the loading conditions - internal pressure of the cooling air and the external aerodynamic pressure on the vane were considered as random variables with assumed distributions and nominal values for the means and coefficients of variation.

\section{Estimation of Weibull Parameters}

The stochastic behavior of the $\mathrm{SiC} / \mathrm{SiC}$ in-plane Young's Modulus and proportional limit strength at $1200{ }^{\circ} \mathrm{C}$ were characterized from experimental data using the 2-parameter Weibull distribution. This information was subsequently included in the probabilistic analysis. The 2-parameter Weibull distribution is expressed as:

$$
\mathrm{P}=1-\exp \left\{-\left(\frac{\alpha}{\beta}\right)^{\gamma}\right\}
$$


where $\mathrm{P}$ is the probability of occurrence, $\alpha$ is the particular value of data for which probability is to be calculated, $\beta$ is the Weibull characteristic value - the value where the probability of occurrence is $63.21 \%$ - and $\gamma$ is the Weibull modulus which measures the degree of dispersion or scatter in the data. For the composite proportional limit strength - which could be regarded as a strength measurement $-\alpha$ is a value of strength while $\beta$ is the characteristic strength. Both $\alpha$ and $\beta$ have units of stress. The Weibull modulus $\gamma$ is dimensionless. As $\gamma$ increases the amount of dispersion decreases. Typical values describing monolithic ceramic strength dispersion range from about 5 to more than 30 . Ceramic composites likely fall within this same range. $P$ in equation (1) is interpreted as a probability of failure when the distribution is used to describe strength. Likewise, characterizing the in-plane Young's modulus using the Weibull distribution, $\alpha$ is the value of Young's modulus, $\beta$ is the characteristic value, and $\alpha$ and $\beta$ both have units of stress.

Results from the measurements of the in-plane elastic modulus for 24 specimens made from flat $\mathrm{SiC} / \mathrm{SiC}$ panels shown in figure 5 in the form of a Weibull plot. From figure 5 it can be seen that there is moderate scatter in Young's modulus, where the mean of the data is $181.5 \mathrm{GPa}$ and the standard deviation is $13.8 \mathrm{GPa}$ with a coefficient of variation of $7.6 \%$. For the Weibull distribution the scatter is described with the Weibull modulus $\gamma$ which has a value of 14.1. The data visually shows a good fit to the 2parameter Weibull distribution. Fitting a 3-parameter Weibull distribution to the data would yield improved goodness-of-fit scores, however there are too few data points to conclude with any reasonable certainty that the underlying distribution has a 3-parameter Weibull behavior.

Results from the measurements of the in-plane proportional limit strength for 24 specimens and the best-fit Weibull line obtained from maximum likelihood analysis are shown in figure 6 . The mean of the data is $166.0 \mathrm{MPa}$ and the standard deviation is $27.2 \mathrm{MPa}$ with a coefficient of variation of $16.4 \%$. The Weibull modulus $\gamma$ has an estimated value of 7.4 which indicates considerably more scatter than the inplane modulus data. The variation in the material properties can be due to intrinsic variation in the constituent material properties, geometry and fabrication induced parameters. The Kolmogorov-Smirnov (K-S) (ref. 12) and Anderson-Darling (A-D) (ref. 12) goodness-of-fit significance levels were 87\% and $74 \%$, respectively, which indicates a good fit across the entire range of data to the estimated parameters.

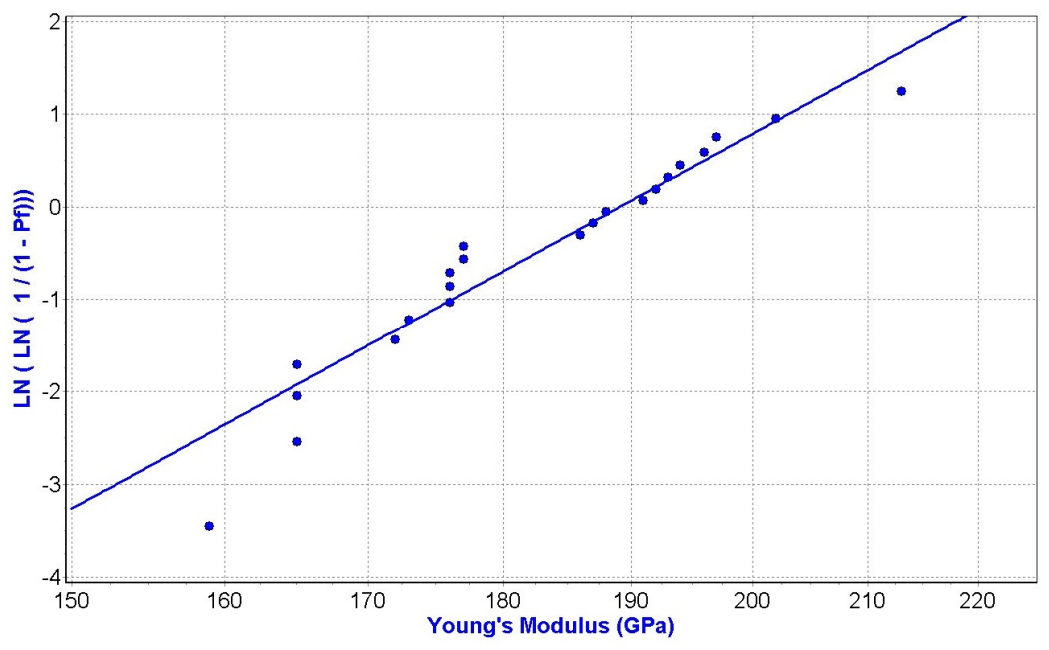

Figure 5.-Weibull plot of ceramic composite in-plane Young's modulus. A best fit line through data is also shown. 


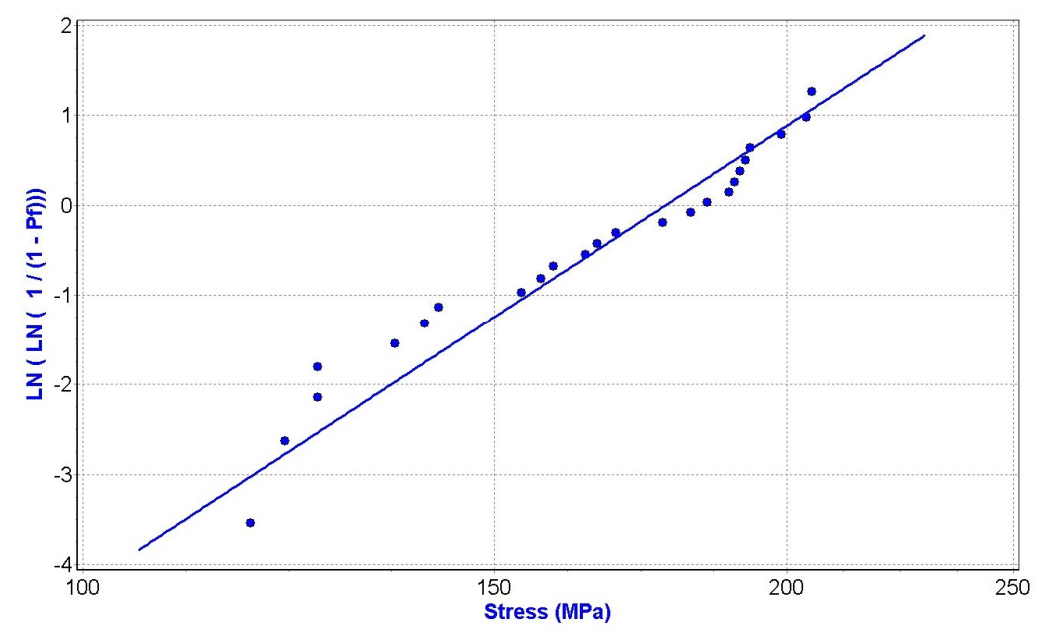

Figure 6.-Weibull plot of ceramic composite in-plane proportional limit strength. A best fit line through the data is also illustrated.

The $90 \%$ confidence bounds on the estimated parameters show the uncertainty range as to the true values of the parameters, which in this case ranges between 9.2 and 5.3 for $\gamma$ and 187.0 and 168.7 for $\beta$. The inplane proportional limit strength Weibull parameter estimates were also based on 24 measurements which, as noted before, yielded reasonably narrow confidence bounds. In summary, both the in-plane modulus and proportional limit strength data fit the 2-parameter Weibull distribution reasonably well. The degree of scatter was considerably larger in the proportional limit strength data than the in-plane modulus data. The sample size of 24 for each measured quantity provided an adequate degree of confidence that the estimated parameters were representative of their true values. The degree of scatter in the data in both figures 5 and 6 highlight the necessity of using probabilistic methodology in any risk assessment of a component to meet its design requirements.

\section{Probabilistic Analysis Approach}

Design requirements dictate that a structure satisfy various criteria of safety, serviceability and durability under the action of anticipated loads during its useful lifetime. In other words, the structural strength or resistance should be greater than the effects caused by the action of loads. A simplified model (referred to as S-R model) consists of two variables (one relating to loads, $\mathrm{S}$, and the other to the strength or resistance, $\mathrm{R}$, of the structure) as shown in figure 7. Both $\mathrm{R}$ and $\mathrm{S}$ are random in nature and that randomness is characterized by their respective probability density functions. The nominal (deterministic) values, $S_{N}$ and $R_{N}$, used in safety factor based approach, are also shown in figure 7 . In a deterministic approach, the design safety is assured by requiring that the $R_{N}$ be greater than $S_{N}$ with a specified safety margin. A safe design requires that the condition of $R_{N}>S_{N}$ at all times. The intent of this approach and other similar deterministic approaches can be understood by considering the area of the overlap of two probability density functions (shaded region), which provides a measure of the probability of failure. This overlap depends upon

1. The relative positions of the curves represented by the mean values $\left(\mu_{S}\right.$ and $\left.\mu_{R}\right)$ of the two variables $\mathrm{S}$ and R. As the distance between the two curves increase, the area of the overlap (probability of failure) decreases.

2. The dispersion of the two curves is characterized by the standard deviations $\left(\sigma_{S}\right.$ and $\left.\sigma_{R}\right)$ of the two variables $\mathrm{S}$ and $\mathrm{R}$. For narrower curves, the area of overlap and thus the probabilities of failure are smaller.

3. The shape of the curves that are represented by the probability density functions. 


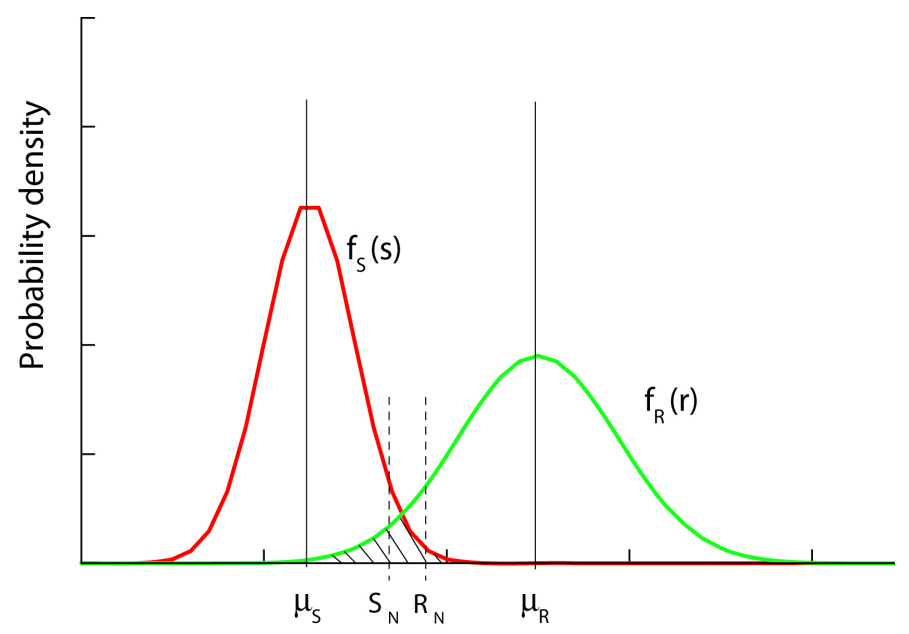

Figure 7.--Intersection of probability density functions for stress (load) $f_{S}(S)$ and strength (resistance) $f_{R}(R)$ define the failure probability

To achieve a safe design, the design variables must be chosen such that the area of overlap is minimized. The basic concept of the classical theory of structural reliability and risk-based design starts with the identification of relevant load and resistance parameters, called basic variables or sometimes referred to as random variables, $X_{i}$ (such as loads, material properties, etc.) and the functional relationship between the response variable, $\mathrm{Z}$ (e.g., stress at a point, deflection, frequency etc.) and the basic random variables.

For over two decades, NASA Glenn Research Center in conjunction with Southwest Research Institute has been involved in developing efficient probabilistic analysis tools for aerospace applications. As a result of this effort, a collection of methods called Fast Probability Integration (FPI) techniques were developed to solve a large class of engineering problems (ref. 13). In the current work, the FPI approach is implemented as illustrated in the following procedure:

1. A set of input random variables are identified and the corresponding probabilistic distributions are selected. For a given set of random variables, a deterministic analysis is conducted using a finite element analysis code. The response results are collected from the finite element analysis output.

2. The above process is repeated a number of times to generate a table of response variable values that correspond to the perturbed values of the selected input random variables.

3. The FPI analysis then uses the previously generated table to compute the cumulative distribution function $(\mathrm{CDF})$ and corresponding sensitivities of the response.

In addition to the CDF of the response, the FPI technique provides additional information regarding the sensitivity of the response to the random variables as shown schematically in the flow diagram of figure 8 . Sensitivity defines the effect of a random variable with its scatter on the overall probability of failure. The magnitude of the sensitivity factor provides a way to rank the random variables that have the most influence on the uncertainty of the response variable. This helps the user to prioritize the data collection resources. Also, by controlling scatter in the more significant variables, the reliability can be improved. 


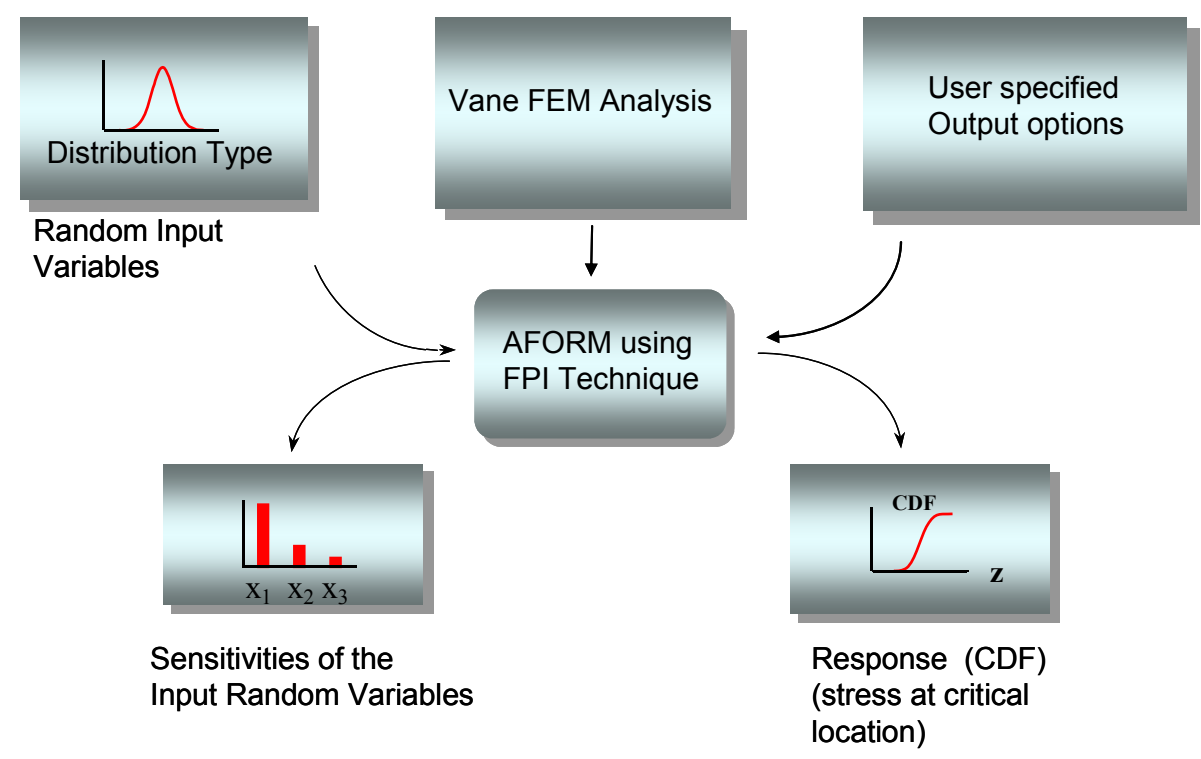

Figure 8.-Probabilistic analysis flow chart.

\section{CMC Stator Vane Example}

As mentioned in an earlier section, two cases were evaluated for the risk assessment of the vane design as described below (ref. 14).

\section{Case I}

Young's modulus (E), Poisson's ratio (v), coefficient of thermal expansion $(\alpha)$ for computing the variability in the stress and the proportional limit strength of the material were considered random variables. Other parameters were assumed to be deterministic for this analysis. The modulus and proportional limit strength statistics were based on the observed scatter (measured data) and the Weibull parameter analysis described earlier. Description of test specimen and experimental details are provided in reference 5. The probabilistic analysis, using the advanced first order reliability method (AFORM), one of the methods in FPI collection, is done in two steps. The first step involves the computation of the probabilistic characteristics (mean value and standard deviation) of the hoop stress at the critical location. The Young's modulus has the highest effect on the variability of hoop stress among the random variables selected. The second step involves risk quantification by employing the basic R-S reliability model. S represents the computed stress at the critical location and $\mathrm{R}$ is the resistance (strength/proportional limit) based on the observed scatter and the Weibull parameter analysis described earlier. By using AFORM, the probability of failure is computed as 0.00994 (approximately 10 failures out of 1000). Sensitivity information from this analysis indicates that the scatter in strength virtually controls the reliability of the vane design. It is worth mentioning again that since the vanes were originally designed to assure that the maximum stresses will be below the proportional limit stress, failure simply means that the vane design fails to meet this criterion, i.e., maximum stress exceeding the proportional limit stress.

\section{Case II}

In the second case, two additional variables namely internal cooling air pressure and external aerodynamic pressure on the vane were added as random variables. As mentioned previously, external aerodynamic pressure on the vane was computed using a CFD analysis. Since no measured data on 
pressures was available, the study was conducted as a sensitivity study to evaluate the effect of certain loading parameters. The internal cooling air pressure is assumed to be normally distributed with a mean value of $862 \mathrm{kPa}$ and a coefficient of variation (COV) of 0.04 (i.e., a standard deviation of $34 \mathrm{kPa}$ ). The external aerodynamic pressure is also assumed to be normally distributed with a mean value of $552 \mathrm{kPa}$ and a COV of 0.08 . As expected, the loading parameters, namely the internal and external pressures, are the dominant ones that control the scatter in hoop stress. Therefore, the scatter in the loading parameters, namely internal and external pressures should be established by experimental measurements. The stress distribution is used to quantify risk by using the standard R-S model. Accordingly, the probability of failure is computed as $0.0162(\sim 1.6 \%$ or 16 out of 1000 failures). In this case, stress uncertainty also contributes to this failure probability. The higher failure probability is due to an increase in uncertainty of hoop stress, which, in turn, occurs because of the inclusion of loading parameters as random variables. A summary of the risk assessment for both cases is shown in figure 9 .

\section{Current Work}

Current work is primarily focused on establishing confidence limits to probabilistic life predictions. A sample result from this work in progress is presented here. Since the measured data for the ceramic composite properties is very limited, 90 and $95 \%$ confidence intervals were also computed for material modulus and the proportional limit strength. A preliminary result for the failure probability with the confidence bounds is shown in figure 10 using the above properties. Results show that the probability of failure $(\mathrm{R}=\mathrm{S}$ i.e., $\mathrm{R}-\mathrm{S}=0)$ is approximately $1.6 \%$ as computed before. However, the failure probability for $95 \%$ confidence limit ranges from 0.6 to $4 \%$. This work on assessing confidence intervals is still work in progress and will be elaborated in future publications.

\begin{tabular}{c|c} 
Case & Failures \\
\hline 1 & $10 / 1000$ \\
2 & $16 / 1000$
\end{tabular}

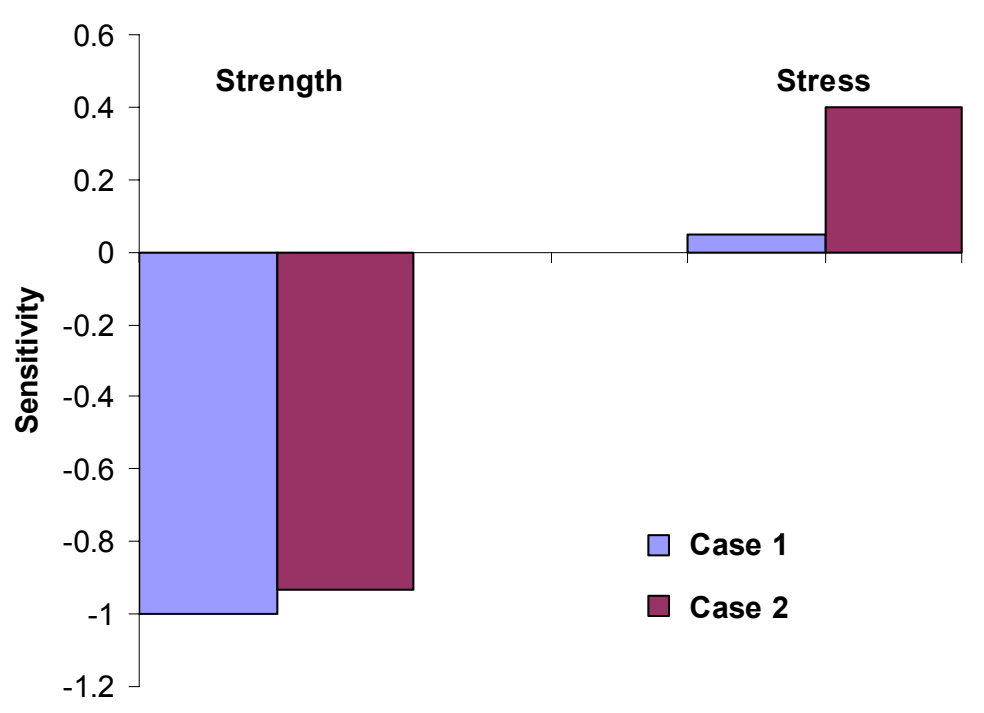

Figure 9.-Summary of risk analysis results. 


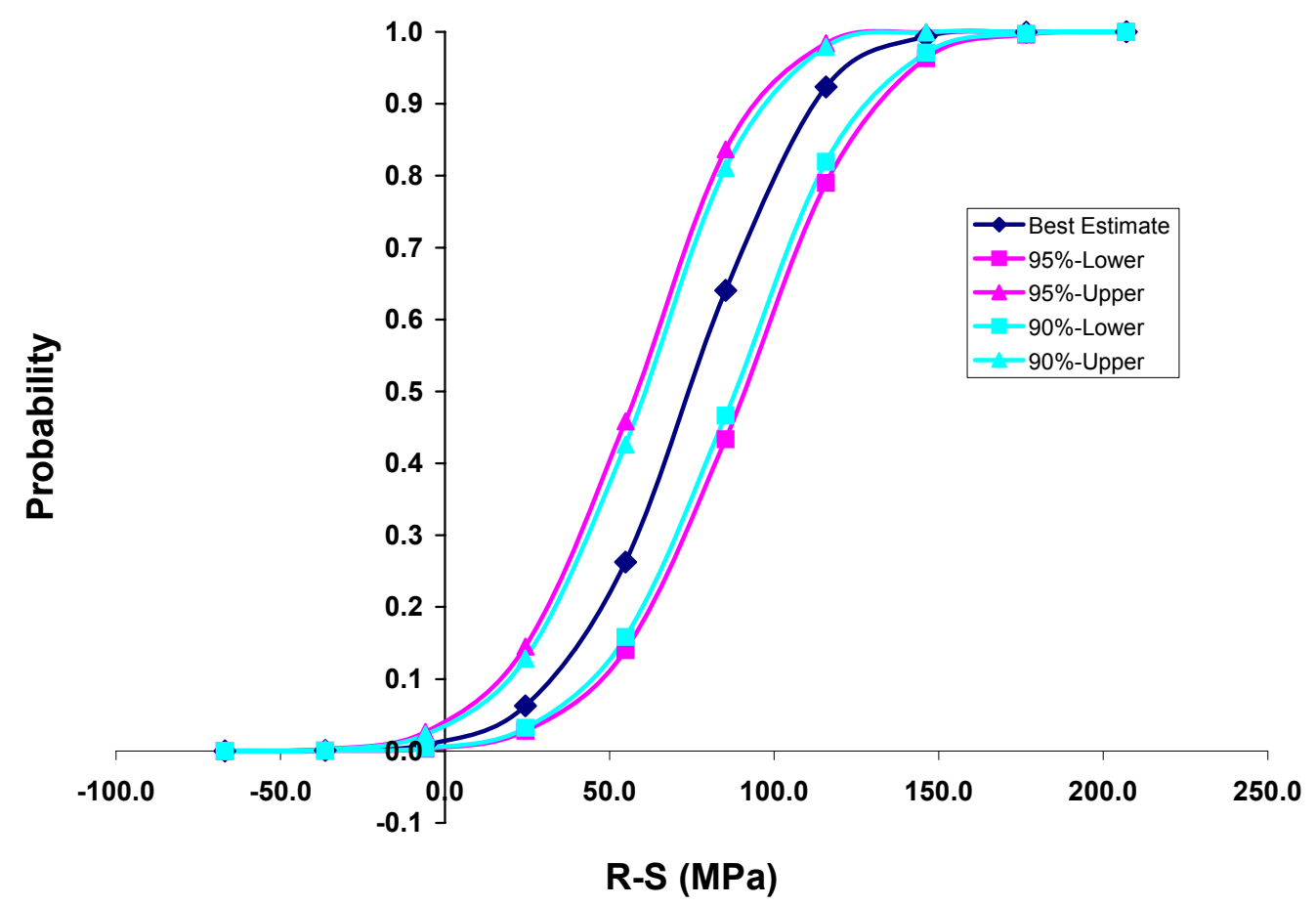

Figure 10.-Cumulative probability functions of R-S for the turbine stator vane with 90 and 95\% confidence bounds (Case II), R-strength, S-stress.

\section{Summary}

High temperature ceramic matrix composites are potential candidate materials for hot section gas turbine components. This paper presented a review of the life prediction and probabilistic analyses for a CMC turbine stator vane subjected to typical operating conditions, performed during the last five years by the authors. A computer code NASALife was used to analyze a ceramic composite turbine stator vane subjected to a typical mission cycle loading that induces mechanical cyclic and creep loading conditions. Although a complete set of results is not presented in this review paper, results show that the NASALife computer code provides a good engineering estimate for the life of the structural component with the expected trends. A full range of material properties data is required to make any kind of plausible life prediction. In particular, the data must cover the operating conditions for which the analysis is to be conducted.

In addition, a finite element analysis coupled with AFORM probabilistic analysis method was used to conduct a reliability assessment of the same ceramic composite turbine stator vane. Results showed that the load related parameters have a more significant effect on the uncertainty in hoop stress than materialor geometry-related parameters. Based on the sensitivity analysis, the most effective way to improve the reliability of the vane would be by reducing the scatter in the proportional limit strength of the vane material.

\section{References}

1. DiCarlo, J.A., Yun H-M, Morscher, G.N. and Bhatt, R.T, 2004.: SiC/SiC Composites for $1200{ }^{\circ} \mathrm{C}$ and Above. NASA Technical Memorandum, NASA/TM-2004-213048.

2. Calomino, A.M., 2002: Mechanical Behavior and Characterization of $1316^{\circ} \mathrm{C}$ In-situ BN Coated $\mathrm{MI} / \mathrm{SiC} / \mathrm{SiC}$ Composite, Available from NASA Glenn Research Center, Cleveland, $\mathrm{OH}$. 
3. Verrilli, M.J., 2003: CMC Vane Subelement Fabrication and Testing in a Gas Turbine Environment. Available from NASA Glenn Research Center, Cleveland, $\mathrm{OH}$.

4. Thomas, D.J. and Srivastava, R., 2003: Analysis of CMC Vanes Subjected to Gas Turbine Environment Testing. Proc. of $27^{\text {th }}$ Annual Conference on Composites, Materials and Structures Jan. 27-31, 2003, Cocoa Beach, Cape Canaveral, FL.

5. Kalluri, S., Calomino, A.M. and Brewer, D.N., 2002: High-Temperature Tensile Properties and Fatigue Behavior of a Melt-Infiltrated $\mathrm{SiC} / \mathrm{SiC}$ Composite. Proc. Eight International Fatigue Conf., Stockholm, Sweden, 3-7 June 2002, pp. 1965-1972.

6. Walker K., 1970: The Effect of Stress Ratio during Crack Propagation and Fatigue for 2024-T3 and 7075-T6 Aluminum, Effects of Environment and Complex Load History on Fatigue Life. ASTM STP 462, American Society for Testing and Materials: Conshohocken, PA, pp. 1-14.

7. Gyekenyesi, J.Z., Murthy, P.L.N. and Mital, S.K., 2005: NASALIFE-Component Fatigue and Creep Life Prediction Program. NASA Technical Memorandum, NASA/TM-2005-213886.

8. Endo., T., Mitsunaga, K., Nakagawa, H. and Ikeda, K., 1992: Fatigue of Metals Subjected to Varying Stress - Low Cycle, Middle Cycle Fatigue. Preliminary Proceedings of the Chugoku-Shikoku District Meeting, The Japan Society of Mechanical Engineers, Nov. 1967, pp. 45-48 and The Rainflow Method in Fatigue. Ed. by Murakami, Y. Butterworth-Heinemann Ltd, Boston, ISBN 0750605049. p. xi

9. Miner, M. A., 1945: Cumulative Damage in Fatigue. Journal of Applied Mechanics, vol. 12, no. 3, pp. A159-A164.

10. Larson, F. R. and Miller, J., 1952: A Time-Temperature Relationship for Rupture and Creep Stresses. Trans. ASME, vol. 74, p. 765.

11. Gyekenyesi, J.Z., Murthy, P.L.N. and Mital, S.K., 2005: Life Prediction of a CMC Component Using the NASALIFE Computer Code. NASA Technical Memorandum, NASA/TM-2005-213887.

12. Nemeth, N. N., Powers, L. P., Janosik, L. A., and Gyekenyesi, J. P., 2003: Ceramics Analysis and Reliability Evaluation of Structures Life Prediction Program. NASA Technical Memorandum, NASA/TM-2003-106316.

13. NESSUS (Numerical Evaluation of Stochastic Structures Under Stress) Computer Code, Version 6.2, User's Guide, Southwest Research Institute, Nov. 1995.

14. Murthy, P.L.N., Nemeth, N.N., Brewer, D.N. and Mital, S.K., 2004: Probabilistic Analysis of a $\mathrm{SiC} / \mathrm{SiC}$ Ceramic Matrix Composite Turbine Vane. NASA Technical Memorandum, NASA/TM2004-213331. 


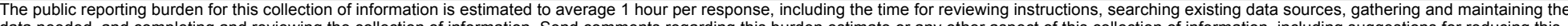

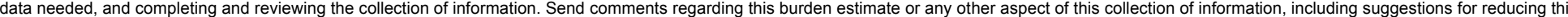

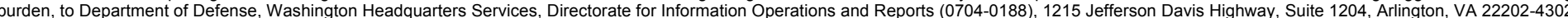

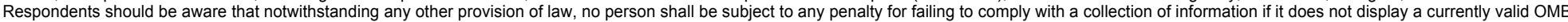
control number.

PLEASE DO NOT RETURN YOUR FORM TO THE ABOVE ADDRESS.

\section{REPORT DATE (DD-MM-YYYY) \\ 2. REPORT TYPE \\ 3. DATES COVERED (From - To)}

01-09-2007

Technical Memorandum

\section{TITLE AND SUBTITLE}

Reliability and Creep/Fatigue Analysis of a CMC Component

5a. CONTRACT NUMBER

5b. GRANT NUMBER

5c. PROGRAM ELEMENT NUMBER

\section{AUTHOR(S)}

Murthy, Pappu, L., N.; Mital, Subodh, K.; Gyekenyesi, John, Z.; Gyekenyesi, John, P.

\section{5d. PROJECT NUMBER}

5e. TASK NUMBER

5f. WORK UNIT NUMBER

WBS 599489.02.07.03.02.02.02

\section{PERFORMING ORGANIZATION} REPORT NUMBER

E-16136

National Aeronautics and Space Administration

John H. Glenn Research Center at Lewis Field

Cleveland, Ohio 44135-3191

\section{SPONSORING/MONITORING AGENCY NAME(S) AND ADDRESS(ES)}

National Aeronautics and Space Administration

Washington, DC 20546-0001

\section{SPONSORING/MONITORS ACRONYM(S) \\ NASA \\ 11. SPONSORING/MONITORING REPORT NUMBER \\ NASA/TM-2007-214975}

\section{DISTRIBUTION/AVAILABILITY STATEMENT}

Unclassified-Unlimited

Subject Category: 24

Available electronically at http://gltrs.grc.nasa.gov

This publication is available from the NASA Center for AeroSpace Information, 301-621-0390

\section{SUPPLEMENTARY NOTES}

\section{ABSTRACT}

High temperature ceramic matrix composites (CMC) are being explored as viable candidate materials for hot section gas turbine components. These advanced composites can potentially lead to reduced weight and enable higher operating temperatures requiring less cooling; thus leading to increased engine efficiencies. There is a need for convenient design tools that can accommodate various loading conditions and material data with their associated uncertainties to estimate the minimum predicted life as well as the failure probabilities of a structural component. This paper presents a review of the life prediction and probabilistic analyses performed for a CMC turbine stator vane. A computer code, NASALife, is used to predict the life of a 2-D woven silicon carbide fiber reinforced silicon carbide matrix (SiC/SiC) turbine stator vane due to a mission cycle which induces low cycle fatigue and creep. The output from this program includes damage from creep loading, damage due to cyclic loading and the combined damage due to the given loading cycle. Results indicate that the trends predicted by NASALife are as expected for the loading conditions used for this study. In addition, a combination of woven composite micromechanics, finite element structural analysis and Fast Probability Integration (FPI) techniques has been used to evaluate the maximum stress and its probabilistic distribution in a CMC turbine stator vane. Input variables causing scatter are identified and ranked based upon their sensitivity magnitude. Results indicate that reducing the scatter in proportional limit strength of the vane material has the greatest effect in improving the overall reliability of the CMC vane.

15. SUBJECT TERMS

Life prediction; Turbine vane; Creep rupture; Low cycle fatigue; Probabilistic analysis; Scatter; Proportion limit

\begin{tabular}{|c|c|c|c|}
\hline \multicolumn{3}{|c|}{ 16. SECURITY CLASSIFICATION OF: } & \multirow{2}{*}{$\begin{array}{l}\text { 17. LIMITATION OF } \\
\text { ABSTRACT } \\
\text { UU }\end{array}$} \\
\hline $\begin{array}{l}\text { a. REPORT } \\
\text { U }\end{array}$ & $\begin{array}{l}\text { b. ABSTRACT } \\
U\end{array}$ & $\begin{array}{l}\text { c. THIS } \\
\text { PAGE } \\
\text { U }\end{array}$ & \\
\hline
\end{tabular}

18. NUMBER
OF
PAGES
19

19a. NAME OF RESPONSIBLE PERSON
STI Help Desk (email:help@ sti.nasa.gov)
19b. TELEPHONE NUMBER (include area code)
301-621-0390



